\title{
INTERSPECIFIC HYBRIDIZATION AND THE EVOLUTIONARY ORIGIN OF A GYNOGENETIC FISH, POECILIA FORMOSA
}

\author{
Bruce J. Turner ${ }^{1,3}$, Betty-Lou H. Brett ${ }^{1,2}$, And Robert R. Miller ${ }^{1}$ \\ ${ }^{1}$ Museum of Zoology and 'School of Natural Resources, University of Michigan, Ann Arbor, Michigan 48109
}

Received November 15, 1979. Revised February 11, 1980

In recent years, largely through the application of allozyme techniques, several unisexual (thelytokous) vertebrates have been shown to be genetically equivalent to $F_{1}$ hybrids of certain related bisexual species. The causal relationship, however, between interspecific hybridization and the origin of unisexuality has not been elucidated, and the role of hybridization per se is controversial (Cuellar, 1974, 1977, 1978; Cole, 1978; Wright, 1978). The amazon molly, Poecilia formosa (Girard), an ovoviviparous gynogentic teleost (family Poeciliidae) was the first known unisexual vertebrate (Hubbs and Hubbs, 1932). The discoverers of its unisexuality recognized early that it was probably of hybrid origin, as it was an almost exact morphological intermediate between the sailfin molly (Poecilia latipinna) and the shortfin mollies (which were then regarded as a single species, $P$. sphenops). Laboratory hybridization of the presumptive parental species, however, produced only bisexual progeny, including fertile males (Hubbs, 1933, 1955, 1961; Meyer, 1938; Hubbs and Hubbs, 1946a, 1946b). Subsequent to those early hybridization experiments, $P$. "sphenops," as it was then recognized, has been shown to be an assemblage of morphologically similar but genetically quite distinct species (Hubbs, 1961; Schultz and Miller, 1971; Miller, 1975; Brett et al., unpubl.). A variety of zoogeographic, morphological (Darnell and Abramoff, 1968), chromosomal (Prehn and Rasch, 1969), and biochemical genetic (Abramoff et al., 1968; Turner et al., 1980) data suggest that the shortfin species involved in the ancestry of $P$. formosa was $P$. mexicana, a species restricted to the

\footnotetext{
${ }^{3}$ Present address: Department of Biology, Virginia Polytechnic Institute and State University, Blacksburg, Virginia 24061.
}

Atlantic slope of Mexico and Guatemala. The stocks of shortfin mollies used by the Hubbses (and by Meyer, who obtained his material from them) were descended largely from progenitors collected on the Pacific coast of Mexico near Acapulco (L. C. Hubbs, pers. comm.). They were therefore most likely $\boldsymbol{P}$. butleri or $\boldsymbol{P}$. sphenops (both sensu Schultz and Miller, 1971), or perhaps inadvertent laboratory hybrids of one of these species with the other or with $P$. mexicana. In other words, the attempts to produce gynogenetic $P$. formosa in the laboratory by interspecific hybridization were probably done with what later turned out to be at least one "wrong" species.

To our knowledge, there have been no subsequent attempts to produce gynogens by interspecific hybridization of Poecilia species. Prompted by this, and by the successful laboratory "synthesis" of hybridogenetic unisexual Poeciliopsis by direct hybridization of bisexual progenitor species (Schultz, 1973, 1977), we hypothesized that hybridization of the "correct" Poecilia species should produce at least some gynogenetic progeny. Moreover, if gynogens could be easily synthesized, the interfertility of other shortfin mollies in laboratory crosses would provide a ready-made system (complete with allozyme markers) in which the genetic bases of hybrid unisexuality could be studied in detail. The results presented here, however, indicate that our hypothesis was incorrect or at least incomplete; laboratory hybrid progeny of $P$. latipinna and $P$. mexicana are not gynogenetic.

\section{Materials and Methods}

Our experiments took advantage of the relative ease with which mollies can be cultivated and interbred in laboratory aquaria. Hybridization was accomplished 
by combining males and females in the same aquarium and removing broods of young as they appeared. Virgin (spermfree) females, from established laboratory stocks, $P$. mexicana Veracruz and $P$. sphenops Veracruz, were used. The fieldcaught females of other stocks we used were assumed to have stored homospecific sperm before capture. In these cases, the first two broods that each female delivered after being placed with a heterospecific male were considered to be contaminated by homospecific progeny and discarded; the third and subsequent broods were presumed to consist of hybrids. All hybrid broods were reared in individual aquaria. Males were removed as they became evident by their developing fin colors and/or gonopodia, and reared separately.

Sources of parental specimens used in hybridization experiments were as follows: $P$. latipinna Naples-Stock B77-2, canal along Florida Hwy 451; $19 \mathrm{~km} \mathrm{SE}$ Naples, Florida; collected January, 1977. $P$. latipinna Nueces-Stock T77-1, Nueces $\mathrm{R}$, , boat launching inlet at ranger headquarters, Hazel Bazemore State Park, Robstown, Texas; collected February 1977. $P$. formosa have also been taken at this locality (W. S. Moore, pers. comm.) but not by us. $P$. mexicana MonterreyStock M77-39, Ojo de Agua de Apodaca, $32 \mathrm{~km} \mathrm{~W}$ of Hwy 54, near Monterrey, Nuevo Leon, Mexico; collected June, 1977. This stock is presumably referable to the subspecies $P$. $m$. limantouri (Menzel and Darnell, 1973). P. mexicana Veracruz-Stock M66-29; trib. to a lagoon on the Rancho San Gabriel, $38.3 \mathrm{~km} \mathrm{~N}$ of San Jose Cardel, Veracruz, Mexico; linebred laboratory stock, progenitors collected 1966. This stock is presumably referable to the subspecies $P$. m. mexicana (Menzel and Darnell, 1973). P. sphenops Veracruz-Stock M67-2, pond $1 \mathrm{~km} \mathrm{~S}$ of La Piedra bridge, approx. $35 \mathrm{~km} \mathrm{~S}$ of Cd. Veracruz, Veracruz, Mexico; line-bred laboratory stock, progenitors collected 1967.

Tests for gynogenesis. - We used three separate testcross procedures in attempts to detect gynogenetic reproduction among $F_{1}$ hybrid females.
1. Some hybrid females were bred to "tester" male commercial "black mollies." ("Black mollies" are melanistic Poecilia hybrids that are bred in large numbers by the ornamental fish industry. They have had a complex history [e.g., Hubbs, 1936, p. 247, pl. 8], as separate all-black strains were derived by selective breeding from partially black $P$. latipinna, $P$. velifera and possibly from $P$. mexicana and/or $P$. sphenops. These were subsequently hybridized in various combinations. The males we used resembled those of $P$. $l a$ tipinna, and were all from the same source. Shortfin-like strains [sometimes called "Yucatan mollies"] are also available commercially.) When mated to such a tester, nongynogenetic ("bisexual") hybrid females should produce offspring that express some of the paternal genes for black pigment (see Schröder, 1964, for the genetics of black body color in Poecilia). Gynogenetic females, however, should produce progeny that never express the "paternal" genes. This method of detecting potential gynogenesis requires that all test broods be reared until black color genes can be expressed (in some cases, up to $16 \mathrm{wk}$ ).

2. Some hybrid females were bred to tester males of the more distantly related insular species, Poecilia (Limia) vittata. In the laboratory, males of $P$. vittata are efficient "fathers" of pseudogamous $P$. formosa broods (Hubbs and Hubbs, 1946a, $1946 b$; J. S. Balsano, pers. comm.). However, the hybrid cross of $P$. vittata males with females of several bisexual molly species is apparently associated with significant zygote mortality (Schröder, 1965). We therefore reasoned that in an aquarium containing $F_{1}$ hybrid females and a male $P$. vittata of known fertility, any females which became gravid and carried broods to term were likely to be gynogenetic; the broods of nongynogenetic females would fail before parturition, and most likely be resorbed. This method is potentially very efficient, for, unless gynogens are very common among the hybrid progeny, relatively few test broods need be reared. 

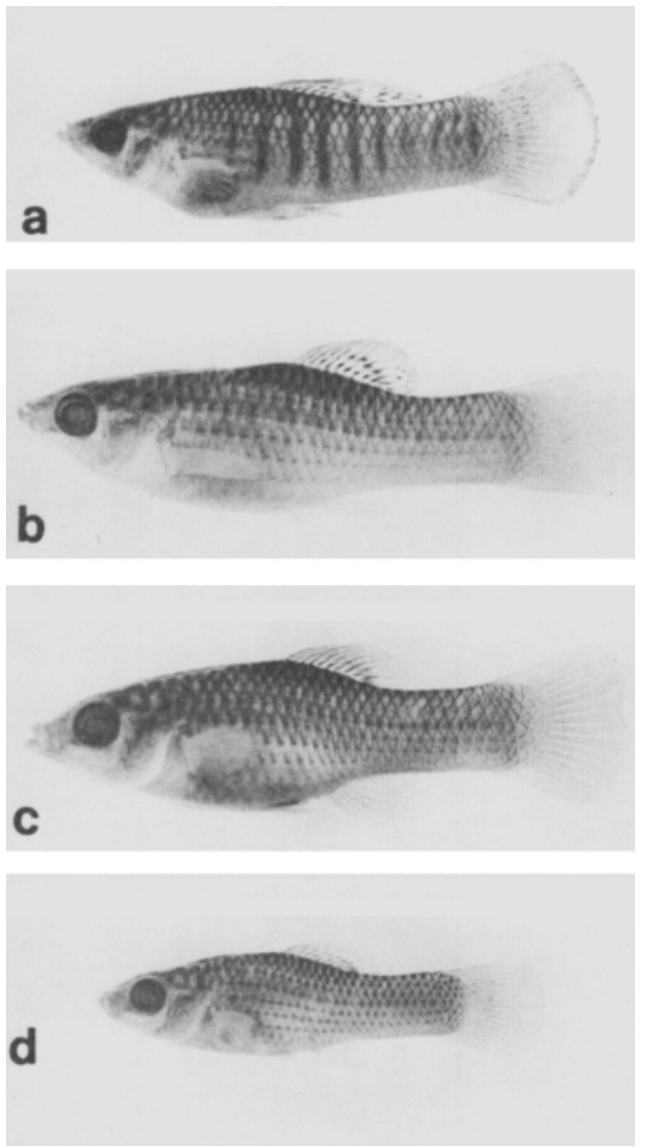

FIG. 1. a. F, hybrid, sexually mature male, 32 mm Standard Length (S.L.); P. latipinna Nueces male $\times P$. mexicana Veracruz female. b. Hybrid as in a female, $37 \mathrm{~mm} \mathrm{S.L.} \mathrm{Progeny} \mathrm{from} \mathrm{the} \mathrm{other}$ interspecific crosses are very similar to these in general appearance. c. Backcross progeny, female 36 $\mathrm{mm}$ S.L.; $F_{1}$ hybrid reciprocal of that in a $\times$ male $P$. mexicana Veracruz. External morphology very similar to that of $P$. mexicana. d. Backcross progeny, female, $27 \mathrm{~mm} \mathrm{S.L.;} \mathrm{F}_{1}$ hybrid as in a $\times$ male $P$. latipinna Nueces. External morphology like that of $P$. latipinna. Parental species and $P$. formosa are figured in Turner et al. (1980).

3. Some hybrid females were backcrossed to males of one of the two parental species or mated to their hybrid brothers. The phenotypes of the resultant young were compared to the $F_{1}$ hybrids.

\section{Results AND Discussion}

A total of $337 \mathrm{~F}_{1} P$. latipinna $\times P$. mexicana (both reciprocals) and $83 \mathrm{~F}_{\mathrm{t}} P$. latipinna $\times P$. sphenops hybrids were produced (Table 1). The following considerations are noteworthy.

1. There is little evidence, if any, of significant zygote mortality associated with any of the hybrid combinations. Brood size was lowest with the two crosses involving $P$. latipinna Nueces females, but, lacking data on the performance of equivalent females when mated to conspecifics, we do not know if these small broods are characteristic of the particular female, the population, the cross, or other factors.

2. All of the crosses produced reproductively competent males as well as females. Two male hybrid $P$. mexicana Veracruz female $\times P$. latipinna Nueces males, chosen at random, were individually backcrossed to female $P$. mexicana; they produced ten broods totaling 98 progeny. Similarly, three males of the reciprocal cross, when backcrossed to female $P$. latipinna, produced 19 broods with 122 progeny. Two $P$. sphenops $\times P$. latipinna hybrid males produced more than 30 young when crossed to $P$. latipinna females. Males were less frequent in the progeny of all the $P$. latipinna $\times P$. mexicana crosses than would be expected on the basis on 1:1 sex ratios (Table 1 " $\mathrm{G}_{\mathrm{p}}$ " values); interbrood heterogeneities (Table 1 , " $\mathrm{G}_{\mathrm{h}}$ " values) were not significant. The combined apparent sex ratio for all of the $P$. latipinna $\times P$. mexicana hybrid progeny was 106 males to 231 females or roughly $1: 2.2$. From the pooled brood data, the sex ratio of the progeny of the $P$. sphenops $\times P$. latipinna cross is not different from $1: 1$, but interbrood heterogeneity of sex ratios in this cross was statistically significant $(P=.03)$ and the difference between it and the three other crosses cannot be evaluated without additional data. The sex ratio data should be treated with some caution, as we lack an estimate of the proportion of $F_{1}$ "females" that were in fact sexually immature males without secondary sexual characteristics; the latter phenomenon is common in our laboratory stocks of $P$. mexicana and in other members of the $P$. sphenops complex. 


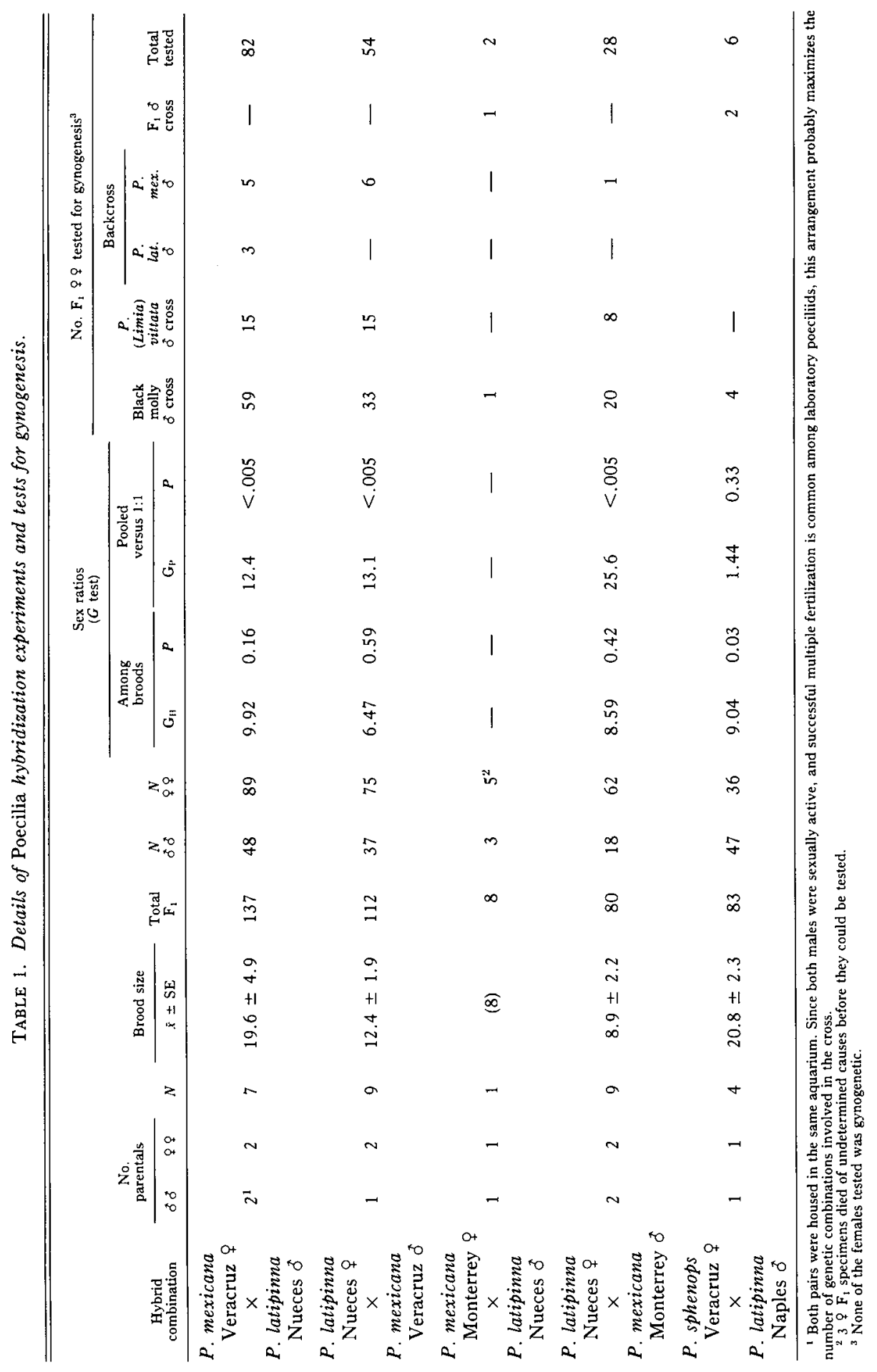


3. The morphology (shape, color patterns, meristics) of the $F_{1}$ hybrids (Fig. 1) was roughly intermediate between the parental extremes. Female hybrids of all crosses were impossible for us to distinguish from laboratory-reared $P$. formosa of comparatle size. The inner jaw teeth of all hybrids we examined are conical and slightly blunted (as they are in $P$. formosa and $P$. latipinna). The dentitions of the $P$. latipinna $\times P$. mexicana hybrids are indistinguishable from those of the $P$. latipinna $\times P$. sphenops hybrids. The genes encoding the distinctly tricuspid inner jaw of the $P$. sphenops parent are evidently recessive to those encoding the conical teeth of $P$. latipinna, a finding seemingly at variance with the partial dominance of conical teeth in other $P$. sphenops hybrids (Schultz and Miller, 1971). The morphology of the hybrids and of their backcross progeny will be dealt with in more detail elsewhere.

4. No gynogens could be identified among the $F_{1}$ hybrid females.

a. None of the 38 females bred to male $P$. (Limia) vittata males produced any progeny.

b. Of the $121 \mathrm{~F}_{1}$ females bred to "tester" male black mollies, 25 produced broods; each of these was reared separately. All tester progeny, without exception, showed definite expression of paternal genes for black body coloration. Considerable variation was noted among broods in the time at which the paternal genes were expressed; in some broods the black markings were evident within a week of birth, but in others, sometimes with the same father, expression was delayed, in one case up to about 16 weeks after birth. The test progeny have blotchy or reticulated color patterns with little bilateral symmetry; progeny with similar markings are produced when black molly tester males are mated to $P$. latipinna females. At present we do not know why only about a fifth of the $F_{1}$ females that were bred to black molly tester males actually produced progeny. We suspect that some newly-born broods may have been lost to maternal predation before we could detect and remove them. Limited fertility of tester males may also have been a problem.

c. Backcross progeny were intermediate in phenotype between the $F_{1}$ hybrids and the parental species (Fig. 1).

The apparent lack of gynogenesis in any of the $P$. latipinna $\times P$. mexicana hybrid females tested is surprising in view of all the other data which suggest that these two species are involved in the ancestry of $P$. formosa. Our failure to produce gynogenetic progeny by laboratory hybridization of the putative parental species could be reasonably explained by either of the following two hypothesis.

1. Despite the wealth of morphological, allozyme, and other data, at least one parental species has been misidentified. Our allozyme surveys of the Mexican components of the $P$. sphenops complex (Brett et al., unpubl.; Brett, unpubl.) have now become extensive, and it is clear that $P$. mexicana provides by far the best "match" with the genome of $P$. formosa of any member of that complex. Evaluation of this hypothesis should therefore focus primarily on members of the $P$. latipinna complex, most especially $P$. petenensis. The latter species, unknown genetically, is morphologically rather similar to $P$. $l a$ tipinna.

2. There are particular "gynogenetic genotypes" among the genomes of at least one of the parental species that result in gynogenesis upon hybridization. The frequency of these genotypes varies geographically and perhaps temporally. They are rare or absent in the populations we tested (we thus obtained only bisexual progeny), but are (or were) more common in others, including the actual progenitors of $P$. formosa. If this hypothesis is correct, it follows that the differences between gynogenetic and nongynogenetic genotypes are probably small in magnitude, and, at the extreme, may involve allelic differences at but a single locus. The evolutionary origin of parthenogenesis in $P$. formosa and other unisexuals may, therefore, reside not in the wholesale interaction of the two divergent components of a hybrid genome (as seems widely held) 
but in the action of certain alleles at one or a few loci that have been placed, by hybridization, into a novel genetic environment.

\section{ACKNOWLEDGMENTS}

We thank R. M. Bailey and M. L. Smith for collecting specimens in the field, J. Humphries for helpful discussions, and P. Monaco and R. Andrews for critical readings of the manuscript. We also thank Mrs. L. C. Hubbs for her time-consuming plunge into old records and discussions of her Poecilia hybridization work. Research supported in part by NSF grants DEB7620958 (BJT) and DEB77-17315 (RRM).

\section{Literature Cíted}

Abramoff, P., R. M. Darnell, and J. S. BalSANO. 1968. Electrophoretic demonstration of the hybrid origin of the gynogenetic teleost $P o e$ cilia formosa. Amer. Natur. 102:555-558.

Cole, C. J. 1978. Parthenogenetic lizards. Science 201:1154-1155.

Cuellar, O. 1974. On the origin of parthenogenesis in vertebrates: the cytogenetic factors. Amer. Natur. 108:625-648.

- 1977. Animal parthenogenesis. Science 197:837-843.

- 1978. Parthenogenetic lizards. Science 201:1155.

Darnell, R. M., AND P. Abramoff. 1968. Distribution of the gynogenetic fish Poecilia formosa, with remarks on the evolution of the species. Copeia 1968:354-361.

HubBs, C. L. 1933. Species and hybrids of $\mathrm{Mol}$ lienisia. The Aquarium (Philadelphia) 1:263268, 277.

. 1936. Fishes of the Yucatan peninsula. Carnegie Inst. Wash. Publ. 457:157-287.
1955. Natural hybridization in fishes. Syst. Zool. 4:1-20.

-. 1961. Isolation mechanisms in the speciation of fishes, p. 5-23. In W. F. Blair (ed.), Vertebrate Speciation. Univ. Texas. Symp., Austin.

HubBS, C. L., AND L. C. HubBs. 1932. Apparent parthenogenesis in nature, in the form of a fish of hybrid origin. Science 76:628-630.

1946a. Breeding experiments with the invariably female, strictly matroclinous fish, $\mathrm{Mol}$ lienisia formosa. Genetics 31:218.

- $1946 b$. Experimental breeding of the Amazon molly. Aquarium J. (San Francisco) 17:4-6.

Menzel, B. W., ANd R. M. Darnell. 1973. Systematics of Poecilia mexicana (Pisces: Poeciliidae) in northern Mexico. Copeia 1973:225-237.

MEXER, H. 1938. Investigations concerning the reproductive behavior of Mollienisia formosa. J. Genet. 36:329-366.

Prehn, L. M., and E. M. Rasch. 1969. Cytogenetic studies of Poecilia (Pisces). I. Chromosome numbers of naturally occurring poeciliid species and their hybrids from eastern Mexico. Can. J. Genet. Cytol. 11:888-895

SCHRÖDER, J. H. 1964. Genetische Untersuchungen an domestizierten Stämmen der Gattung Mollienesia (Poeciliidae). Zool. Beitr. 10:369-463.

- 1965. Zur vererbund der Dorsal Flossenstrahlenzahl bei Mollienesia Bastarden. Z. Zool. Syst. Evolut.-Forsch. 3:330-348.

Schultz, R. J. 1973. Unisexual fish: laboratory synthesis of a species. Science 179:180-181.

- 1977. Evolution and ecology of unisexual fishes. Evol. Biol. 10:277-331.

Schultz, R. J., AND R. R. Miller. 1971. Species of the Poecilia sphenops complex in Mexico. Copeia 1971:282-290.

Turner, B. J., B. L. Brett, E. M. Rasch, and J. S. BALSANO. 1980. Evolutionary genetics of a gynogenetic fish, Poecilia formosa, the Amazon molly. Evolution 34:246-258.

Corresponding Editor: J. R. Powell 